\title{
Characterizing social-ecological context and success factors of antimicrobial resistance interventions across the One Health spectrum: Analysis of 42 interventions targeting E. coli
}

\author{
Anaiis Léger ( $\square$ anais.leger@unige.ch ) \\ UNIGE GSI: Global Studies Institute \\ Irene Lambraki \\ University of Waterloo School of Public Health and Health Systems \\ Tiscar Graells \\ Royal Swedish Academy of Sciences: Global Economic Dynamics and the Biosphere

\section{Melanie Cousins} \\ University of Waterloo School of Public Health and Health Systems
}

\section{Patrik JG Henriksson}

Stockholm Resilience Centre

\section{Stephan Harbarth}

UNIGE: Universite de Geneve Faculte de Medecine

\section{Carolee A. Carson}

Public Health Agency of Canada

\section{Shannon E. Majowicz}

University of Waterloo School of Public Health and Health Systems

\section{Max Troell}

Beijer Institute of Ecological Economics: Beijer Institute

\section{Jane E Parmley}

University of Guelph Ontario Veterinary College

\section{Peter S Jørgensen}

Stockholm Resilience Centre

Didier Wernli

Université de Genève Global Studies Institute: Universite de Geneve Global Studies Institute

\section{Research}

Keywords: AMR, social-ecological system, implementation science, Enterobacteriaceae, E. coli

Posted Date: February 22nd, 2021

DOI: https://doi.org/10.21203/rs.3.rs-179136/v1

License: (c) (i) This work is licensed under a Creative Commons Attribution 4.0 International License. Read Full License 


\section{Abstract}

Background. Antimicrobial resistance (AMR) is among the most pressing One Health issues. While interventions and policies with various targets and goals have been implemented, evidence about factors underpinning success and failure of interventions in different sectors is lacking. The objective of this study is to identify characteristics of AMR interventions that increase their capacity to impact AMR. This study focuses on AMR interventions targeting $E$. coli.

Methods. We used the AMR-Intervene framework to extract descriptions of the social and ecological systems of interventions to determine factors contributing to their success.

Results. We identified 52 scientific publications referring to 42 unique $E$. coli AMR interventions. We mainly identified interventions implemented in high-income countries (36/42), at the national level (16/42), targeting primarily one sector of society (37/42) that was mainly the human sector (25/42). Interventions were primarily funded by governments (38/42). Most intervention targeted a low leverage point in the AMR system, (36/42), and aimed to change the epidemiology of AMR (14/42). Among all included publications, 55\% (29/52) described at least one success factor or obstacle (29/52) and 19\% (10/52) identified at least one success factor and one obstacle. Most reported success factors related to communication between the actors and stakeholders and the role of media, and stressed the importance of collaboration between disciplines and external partners. Described obstacles covered data quality, access to data and statistical analyses, and the validity of the results.

Conclusions. Overall, we identified a lack of diversity regarding interventions. In addition, most published E. coli interventions were poorly described with limited evidence of the factors that contributed to the intervention success or failure. Design and reporting guidelines would help to improve reporting quality and provide a valuable tool for improving the science of AMR interventions.

\section{Contributions To Literature}

- Application of AMR-Intervene, a framework to describe AMR interventions, acknowledging the social-ecological and One Health system of AMR in which interventions are embedded.

- Study of 42 coli AMR interventions from a social-ecological system perspective

- Identification of a lack of diversity in the design and implementation of reported coli AMR interventions.

- Identification of several success factors and obstacles associated with AMR interventions

- Reporting of E. coli AMR interventions rarely acknowledge the contextualisation of the intervention, the experience and feedback gained, nor the social-ecological context.

\section{Background}

Antimicrobial resistance (AMR) is a pressing global issue in human and animal health and is frequently included as a priority in political agendas at national and international levels. Over the past ten years, efforts to tackle AMR have increased worldwide. For example, the health care sector adopted tailored stewardship programmes and guidelines for antimicrobial use (AMU) (1) and strengthened surveillance (2). Actions in animal production include industry voluntary bans regarding the use of specific antimicrobials (AM), such as the ceftiofur withdrawal in the broiler industry in Japan (3) and Canada (4,5). Since the adoption of the World Health Organization (WHO) Global Action Plan in 2015, many countries have developed national actions plans, built coordinated national actions, identified targets for interventions and described expected benefits for human health (6). Efforts are also being made to develop a One Health approach by integrating AMR and AMU data from several sectors $(7,8)$. Some integrated programmes have identified several different 
actions that, when implemented together, increase potential for successful reduction of AMR risks (9). All these efforts are reflected in the growing number of interventions being reported in the literature.

In a previous publication, we defined an intervention as coordinated action driven by a social group among a targeted population in a bio-ecological context that interferes with the outcome or course of a difficult situation or process in order to improve it or prevent it from getting worse (10). The term covers a variety of actions, related to the trigger and goal of the intervention, as well as resource availability, context of application, and more. Interventions can also be called initiatives, actions, programmes, and incentive strategies.

AMR issues are the result of complex interactions in tightly coupled social-ecological system (e.g., husbandry system, AM prescription habits, food consumption, and sanitary levels) and should therefore be designed according to their context to maximise impact (11). While individual actions, interventions aim to influence the AMR social-ecological system, how they affect the system depends on their aim, governance, targeted pathogen, and other factors. Hence, implementation science is of critical importance, covering the study of methods and strategies that enhance the translation of evidence-based practice and research into usable material for practitioners and policymakers $(12,13)$. Implementation science provides insights about previous experiences and, as this knowledge grows, aims to identify patterns of intervention success (and failure). This, in turn, can be used to improve our understanding of the factors that contribute to the success or failure of interventions. Some studies have started to identify criteria for implementation of One Health interventions for AMR, e.g., action oriented surveillance systems (14-16). Nevertheless, more evaluations is needed to support success of all actions to address AMR.

The need for systems thinking to support description, study, and evaluation of complex issues such as AMR has been acknowledged in previous publications $(11,17)$. A perspective that stresses the importance of a dynamic, system approach (18) and recognizes the nonlinear, multi-component and the context-dependent nature of interventions can help improve how we address AMR. In the recently published AMR-Intervene framework (10), we outline how AMR interventions can be used to build societal resilience to AMR by implementing actions that influence AMR from its drivers to its impact $(10,19)$. The AMR-Intervene framework is organised into six components: (i) core information about the publication; (ii) social system; (iii) bio-ecological system; (iv) triggers and goals; (v) implementation and governance; and (vi) assessment of the intervention. The framework aims to capture the specific context (e.g., practicality, implementation, acceptability, actors, other interventions implemented, AMR situation) and the broader context (e.g., national AMR governance, level of development of the country) in which the intervention was implemented.

The objective of this narrative review is to identify characteristics of AMR interventions that affect their implementation in social-ecological AMR systems, focusing on interventions targeting resistant Escherichia coli (E. coli). Resistance in gram-negative bacteria, such as $E$. coli, has been identified as one of the most pressing AMR issues $(20,21)$. E. coli is a potential pathogen that is frequently identified in humans and animals and can survive for a long time in the environment. Also, E. coli is considered a good indicator of resistance levels in the community. This study is part of the AMResilience (https://amr-resilience.gtglab.net/) project, which aims to provide and validate a comprehensive multimethod assessment of resilience and transformability to limit AMR and AMU in national and regional One Health systems (22). Here we aim to examine the factors that affect or contribute to intervention success. Enhancing the description of AMR interventions and their social-ecological systems will help increase general knowledge to better design and implement effective AMR interventions.

\section{Methods}

\section{Identification of $E$. coli AMR interventions}


Within the scope of the AMResilience project, we set up a general database of published AMR interventions based on a scoping review of the literature. We used a Boolean query with search strings validated among the co-authors (Annex $A$, Table A1). We searched the PubMed online database in June 2018 (Table A1). As the number of results was large (more than 26,000 records), we narrowed the search to include only literature reviews by adding "publication type" search terms. We screened the publications in three steps: title review, abstract review, and article review (Table A2). The first author conducted the review with support from the last author.

The title review followed the inclusion and exclusion criteria described in Table A3. We defined two exclusion criteria for titles: (i) the title did not state at least one of the following terms: antimicrobial, antibiotic, drug, or resistance; and (ii) the title clearly indicated that the article did not focus on an AMR intervention (e.g., policy comparison papers, recommendation papers, and guidelines). We conducted a title review on all references within the review papers identified and included additional publications in the pool of documents for the abstract review. At this stage, any duplicates were excluded.

The abstract review was conducted for all retained articles based on title review using the inclusion and exclusion criteria described in Table A3. We defined three exclusion criteria for abstracts; (i) abstracts not written in English or French (i.e., languages fluently read from the first and last authors); (ii) abstracts describing theoretical studies with no empirical data presented; and (iii) any of the exclusion criteria of the title review that were not apparent from reading the title only. At this stage, we shared the first list of AMR interventions among the co-authors and asked for relevant interventions or reviews of AMR interventions of their knowledge that were not included.

The article review involved reading and screening the full articles, based on inclusion and exclusion criteria described in Table A4. Articles referring to AMR interventions were selected with no limits were based on the intervention quality, or study type or quality. Instead, the AMR-Intervene database recorded criteria based on the article quality for intervention description and assessment (10).

To avoid missing publications about E.coli, we conducted a new online search specifically targeting E. coli AMR interventions in June 2019 (Table A1 and A2), following the same process as in June 2018. While not exhaustive, this database provides a good basis for evaluating the literature on AMR interventions that specifically target $E$. coli.

\section{Analyses of $E$. coli AMR interventions}

We used the AMR-Intervene framework to code all identified documents referring to $E$. coli AMR interventions. This work was completed between September 2019 and March 2020 by the first author. Every publication was coded by the first author. Also, the last author coded two publications (selected randomly), to be compared with the coding of the first author, to ensure consistency in coding. Problematic coding was discussed with the last author until consensus was reached.

AMR-Intervene is based on an online form built upon a set of questions to facilitate the coding process. Most of the values of the categorical variables used to characterize an intervention were not mutually exclusive. The coder is led with drop-down and multi-choice questions for many of the variables. However, for each question, it is always possible to provide a new value if not included in the current framework. Thus, it is possible to incrementally improve the framework and capture unexpected data. For articles referring to the same intervention, data were merged to conduct analyses by interventions rather than by publications, after checking for consistency. The last part of the AMR-Intervene framework, i.e. assessment, is organized in open questions to capture key results, success/failure factors, and 
unexpected consequences of any intervention. Thus, the framework allows to code key results of the intervention in qualitative and quantitative format.

Descriptive analyses of data from E. coli AMR intervention articles were conducted in R (23). We extracted simple information such as mode, median, minimum and maximum; and computed graphical representation of the data for all relevant variables in the database. Investigating the distribution of data allowed us to capture the diversity of the interventions as well as the most frequent characteristics among all studied interventions. Thus, we were able to capture a typical intervention based on the most representing features of implementation and organisation.

Coding of text from the open-ended questions in the AMR-Intervene was conducted using qualitative analyses software (ATLAS.ti 8 Windows, Scientific Software Development $\mathrm{GmbH}$ ), referencing the text used for each coding. The first author then conducted a thematic analysis of the text extracts following the classification of the framework for advancing science CFIR, Consolidated Framework for Implementation Research (24), but not limited by it if other themes were extracted. This framework gathers criteria of implementation theories in a homogenous terminology. It aims to facilitate the identification of factors and constructs that enhance success across multiple contexts.

\section{Results}

\section{Descriptive analyses of coded articles}

With the review of scientific papers, we identified 52 publications describing and assessing E. coli AMR interventions (Annex A). From the 52 publications selected for this review, 42 different $E$. coli AMR interventions were identified, with four interventions mentioned in two to five papers (Annex C, Table B1 and Figure C1). The coded articles were mainly published after 2015 (Annex B, Figure B2). In Table 1, we detailed the typical E. coli AMR intervention, i.e., summary of the main characteristics from the 42 interventions coded using the AMR-Intervene framework.

Based on qualitative scoring system used in the AMR-Intervene framework, most interventions were poorly described; 28 documents provided insufficient detail, 11 only provided minimal details, and 3 did not provide any assessment of the intervention they described (Figure 1). The study designs for intervention evaluation were mainly cross-sectional (26/52), narrative (7/52), cohort (4/52), time series analyses (3/52), and reviews (3/52). Objectives of the evaluations were not clearly defined in 3 of the 52 publications. Forty-two (42/52) studies used quantitative data for assessment, while the others relied on qualitative assessment. Assessment of interventions was mainly conducted when the intervention was still in progress (31/52).

Only 2 of the 42 interventions were implemented in more than one country. All others were implemented in a single country, most frequently the USA (5/42), Canada (4/42), the Netherlands (4/42), China (3/42) United Kingdom (3/42), and Denmark (3/42). Among the coded interventions, 36 targeted high-income countries, 4 middle high-income countries and 1 a low-income country. The interventions were implemented from 1982 to 2012 (Figure C2). We mainly identified interventions targeting only one sector, either animals (12/42) or humans (25/42) (Figure 2). Interventions targeting humans were predominantly focused on healthcare delivery (24/28) and the general population (2/28). Interventions targeting the animal sector primarily focused on livestock (13/15). Three (3/42) interventions targeted food included meat (2/3) and vegetables (1/3). Only one (1/42) intervention targeted the environment, focusing on wastewater. Most interventions were implemented at the national (16/42), or the local/subnational level (20/42). For the most part, the $E$. coli AMR interventions targeting the animal or human sector had no specific social group targeted, i.e., they focused on the general population. The interventions were implemented in different settings according to the sector targeted. Interventions in animal health were implemented at farms (3/15), slaughterhouse (3/15) or slaughterhouse 
and farm (3/15), or no specific setting (6/15). Interventions targeting human health were mainly implemented in hospitals (21/28). Interventions targeting food mainly targeted supermarkets (2/3).

Among the coded interventions, 29 targeted Enterobacteriaceae in their activities, but not exclusively. 22 interventions targeted more than one type of bacteria, 12 targeted gram positive bacteria, and 10 targeted other gram negative bacteria; 13 interventions targeted no specific bacteria (in these interventions E.coli was an intervention outcome). Interventions usually targeted one class of AM (median=1), but the maximum was seven AM classes (Figure C3). The main targeted AM classes were beta lactams (26/42), quinolones (20/42), and aminoglycosides (15/42), followed by tetracyclines (12/42) and sulphonamides (10/42). Most interventions did not focus on a specific syndrome or disease (33/42), while seven focused on bloodstream infections, six on respiratory diseases (lower and upper tract), and four on urinary tract infections.

Among the coded interventions, most described specific triggers for the intervention (38/42). Most interventions had one specific trigger (31/38), usually the epidemiology state of AMR (15/38) or the health impact of AMR such as the morbidity/mortality (12/38) (Figure 4). In Figure 3, the main policy priorities addressed by the interventions were surveillance (21/42) and conservation of antimicrobials (20/42). The goals of the interventions were mainly to reduce the state of AMR (i.e. the prevalence of pathogens) (25/42) and antimicrobial use (18/42). Among all the interventions, 34 promoted positive action towards AMR control (i.e. promoting to do something right or better), while eight interventions were about restricting or prohibiting something. Finally, among all coded interventions, many targeted a low leverage point in the AMR chain and focused on changing some parameters of the system without addressing the more distal drivers of the emergence and transmission of AMR (36/42).

The main entities responsible for implementation were governments (23/42), some in collaboration with private partners (2/23), followed by research-based organisations (6/42) and private organisations (3/42); also shown in Figure C4. Governments were the principal source of funding supporting AMR interventions (38/42) (Figure C5). Only three publications (3/52), describing two interventions (2/42), clearly mentioned the level/amount of funding for the intervention. Among the interventions and their governance instruments, most used only one type of policy instrument (29/42), mainly using an information strategy (17/42, i.e., encouraging people to act or do something by providing information) and regulation (12/42, i.e., requiring people to do something with potential penalty in case of no compliance). Only seven interventions used two different types of regulations when implementing the activities. Ten interventions (10/42) used self-regulation to address AMR. A clear description of all actors involved in the design and implementation of intervention was only accessible in six publications (6/52), varying from 1 to 56 different actors.

Among reported key results, we identified 101 positive results towards AMR (out of 137 key results reported in total). Key results can be identified as 104 outputs of the interventions and 33 outcomes. Among all key results, we identified 3 related to the drivers of AMR, 37 related to the pressure of AMU towards AMR, 5 related to the impact of AMR, 59 related to the state of AMR, and finally 32 directly related to the intervention and its delivery/implementation/success.

Among all publications, $13 \%$ (7/52) mentioned the identification of positive and negative unintended consequences and six (6/7) described them. The identified unintended consequences can be organised in three categories. First, the intervention enabled hiring of more medical professionals as well as specialists in AM treatments in a hospital. Second, the intervention enhanced a shift in the use of AM from the restricted one to another AM class. And third, authors mentioned issues related to the duration of an intervention's effect suggesting that the observed reduction of AMU might not be permanent. 


\section{Success and failure factors}

Among all coded documents, $55 \%$ of the publications described at least one success factor or obstacle to implementation of the interventions (29/52). Among them, 10 publications $(19 \%, 10 / 52)$ explained at least one success factor and one obstacle. All factors are detailed in Table 2 and additional details of the success factors and obstacles are provided in Table C6. Sixteen of the coded publications described contextual events or factors that were outside the control of implementers that positively or negatively impacted the outcome(s) of the intervention; for example, a concomitant event or a cultural habit.

Success and failure factors included the intervention characteristics (i.e., details about the specific implementation and organisation), the outer and inner settings of the intervention (i.e., changes in context that can influence the intervention), and the implementation process (i.e., planning, engaging, executing and evaluating the intervention). Details are provided in Table 2. Some were classic factors that are mentioned in several publications such as the importance of evidence strength and quality, the importance of tailored intervention, or funding. However, one factor could not be included in the CFIR framework because it could not fit in the categories designed by the framework. One publication mentioned that the intervention might have reached a threshold for intervention effectiveness. Indeed it was argued that the reduction of AMU, limitation of AMR prevalence or any other factors that could enhance the fight against AMR might be limited by the currently feasible action in the system.

\section{Discussion}

This study identified characteristics of E. coli AMR interventions that affect their implementation in social-ecological AMR systems. We used the AMR-Intervene framework to describe the interventions in their diversity regarding the socialecological factors of complex systems, as well as reporting quality in scientific publications. The study of 42 unique $\mathrm{E}$. coli AMR interventions highlighted a lack of diversity of interventions and their action profile, a lack of reporting regarding implementation strategy, and a need in new, adaptive, flexible and complex interventions to tackle AMR.

\section{Lack of diversity of interventions}

The interventions coded in the database had limited diversity, mainly in their social system and governance. Table 1 highlights the homogeneity within the description of the intervention such as spatial homogeneity, small diversity of actors, targeted groups and settings, and similar funding sources. All interventions also targeted the individuals (human or animals) and, except for environmental studies, did not target the cell, gene, or ecosystem level. Also, the sector targeted by the intervention was primarily either human or animal health, and One Health interventions remain rare or not reported. Goals and challenges of collective actions are similar and remain in the same categories; typically, one goal and challenge aiming at reducing the state of AMR through surveillance. The homogeneity of the results of the current research limits our capacity to find successful interventions. As diversity of action is a key driver of resilience in social-ecological system, this might be an obstacle to build societal resilience to AMR.

Moreover, the use of system thinking has highlighted the need for new forms of co-evolutionary governance to tackle AMR $(25,26)$. Numerous studies acknowledge the social-ecological context of AMR, its diversity, its co-dependence and co-evolution with our societies, practices, policies, and technologies $(11,19,27)$. In the same way that we increasingly rely on a specific AM to treat an infectious disease, we are using the same type of interventions to respond to growing AMR. Diversification in actions towards the fights against AMR has been made one of the priorities for successful actions $(11,27)$. Thus, the lack of diversity is also proof of a lack of understanding and/or acknowledgment of the complexity of 
the system, which in turn can decreases the power of actions and interventions $(18,28)$. More geographical diversity is also desired, as most of the interventions identified were implemented in high-income countries, while AMR interventions in low- and middle- income countries have been rapidly increasing over the last decade (29).

\section{Black box of intervention implementation}

From the 52 publications, it seems that factors related to the implementation, sustainability and success of an intervention are part of a black box (30), i.e., these factors are poorly or not reported in scientific publications. The aim of publishing AMR interventions is obviously to report on their effectiveness. Maximizing the usefulness of intervention requires more attention to implementation, including the description of the intervention, its implementation strategy, or the sharing of experience with other people involved in implementation, (11). Also, assessment of the interventions was mainly focused on quantitative indicators, which rationalize and simplify the description process. While this facilitates comparison of intervention results, it obscures the drivers of successes. Furthermore, many different indicators of success or failure were identified in this review. Units and definitions for indicators are not harmonized between evaluations. And still, the main indicators are quantitative, and authors did not explore qualitative methods to assess the interventions. Qualitative assessment of interventions would allow the publication of unusual results or feedback about the intervention and things that may not typically be measured in quantitative assessments of interventions (e.g., social capital, acceptability of the intervention) but may be important to intervention success (28). It could also help assessors to identify unexpected consequences of the intervention. We recognize that authors might not have yet the capacity to report the implementation and assessment of interventions for various reasons (e.g., time constraints, publication restrictions, reluctance to use non validated tools) but believe that the involvement of interdisciplinary team in the design, implementation, evaluation and reporting of interventions can fills this gap.

In most publications we identified a lack of contextualization, as the intervention was not implemented and reported in a global system perspective and usually seen as an individual action. All readers would benefit in knowing the context, the means, and other details of the intervention (31-35). Many studies developed frameworks for reporting and/or assessing interventions (36-41), but few included parameters linked to the social-ecological context of interventions, specifically in an AMR system. The scientific literature is in need of a new definition and understanding of AMR interventions, including a global contextualization of it as we defined an intervention primarily in our study. A new format of publication for health interventions with a systematic description following criteria to ensure minimum details would be an asset for the scientific community and decision makers $(17,42)$.

\section{Limitations - methodology}

This study characterized 42 E. coli AMR interventions using the AMR-Intervene framework. Several limitations could have influenced the results of the study. First, coding bias has been largely prevented, but some variables of the framework still rely on subjective assessment by the coder. Therefore, we implemented a versioning system of AMRIntervene that can be updated depending on research findings and needs of users. Second, the identification of interventions can also be affected by selection bias and affect our capacity to reach them via the online review process. Some interventions might not have clearly mentioned E. coli as a targeted pathogen. For example, interventions targeting many pathogens including $E$. coli among others, interventions based on clinical syndromes (e.g., urinary tract infections, frequently caused by E. coli), as well as all interventions targeting ESBL (extended spectrum beta-lactamase) 
resistance. Finally, our study does not avoid the classical publication bias such as the year of publication, the publication of successful interventions only, publication habits and the dominance of high-income countries in the scientific literature. Details of unsuccessful interventions or even failure factors or difficulties that the implementers faced are rarely reported. Thus, this study should be complemented by a parallel survey to directly reach implementers and better capture success and failure factors, non-published or ongoing interventions that are not covered by this study.

\section{Towards a better understanding and implementation of AMR interventions}

One publication mentioned that activities to fight AMR might have diminishing returns and the reduction of AMU could not be improved by the current means (i.e., AMR interventions as imagined nowadays) and we might need a shift to other more ambitious interventions and/or improvement of intervention implementation.

Improving implementation of interventions is necessary for increasing our capacity to tackle the global issue of AMR. Indeed, there is a need of interventions that are better adapted to their social-ecological context, interventions that are diverse and flexible, with various angles of attack, at all levels of the social and bio-ecological system. However, if interventions are not detailed and reported in a more systematic approach, we might not have sufficient understanding of the current situation of AMR interventions.

A successful intervention should also be able to evolve by integrating feedback and adapting to change. Kruk et al. (43) mentioned that interventions should be integrative, adaptive, self-regulating, diverse, and aware. This would lead to a new generation of complex interventions that would improve how we tackle AMR (11). Diversity in actions and actors may be relevant at the intervention-level, and also at the country or sector-level (e.g., studying interventions from the same sector). On the other hand, diversity should not compromise the use and application of interventions that are effective and work in different context.

Future interventions are also in need of qualitative data about implementation, such as feedback about the experience, success and failure factors, and contextual factors that can impact the effectiveness or continuity of interventions. In this study we gathered a certain number of different success and failure factors, described in the publications. All factors were identified in previous literature but no publications reported factors about the characteristics of individuals involved, the implementation political and economic climate or how the process of executing the intervention among other factors classified by Darmschroder et al. (24). Therefore, there is a need to improve how interventions are assessed, possibly mixing methods of evaluation (28). While contextual factors cannot always be included in the assessment of intervention, mentioning concomitant interventions, even in a different sector, may help understand of the context. A better understanding and overview of a common fight against the AMR issue can also be the aim of a resilient governance system, e.g., listing, gathering, and enhancing AMR interventions in a country.

\section{Conclusions}

The study of E. coli AMR interventions identified several factors that can improve the success of interventions when it comes to tackling resistance in this ubiquitous colonizer and pathogen. The study highlighted the lack of diversity in the design and implementation of reported interventions. We clearly identified a lack of One Health interventions, a trend toward interventions with similar goals, governance, and components of response to AMR. It also pointed out that interventions are not designed using a complex system approach. To support adaptation and transformation (44), the 
fight against AMR is in need of more adaptive, and contextually tailored interventions. We also need to improve how interventions are reported, ideally with guidelines that can be shared among stakeholders in a transparent and comprehensive way. This study should be extended to cover a broader choice of interventions for different pathogens in order to develop an even better understanding and picture of success and failure factors in the battle against AMR.

\section{Abbreviations}

E. coli: Escherichia coli

AM: antimicrobial

AMR: antimicrobial resistance

AMU: antimicrobial use

\section{Declarations}

\section{Ethics approval and consent to participate}

Not applicable.

\section{Consent for publication}

Not applicable.

\section{Availability of data and materials}

The datasets used and analysed during the current study are available from the corresponding author on reasonable request.

\section{Competing interests}

The authors declare that they have no competing interests.

\section{Funding}

This work was funded through an operating grant of the $5^{\text {th }}$ Joint Programming Initiative on Antimicrobial Resistance (JPIAMR 2017). This work was supported by an operating grant from the Canadian Institutes for Health Research (Institute of Infection and Immunity, Institute of Population and Public Health) through the JPIAMR Grant program (PI: S. Majowicz, grant number \#15210), FORMAS (grant number, 2016-00227), and the Swiss National Science Foundation (grant number 40AR40_180189). The funders had no role in the design, analysis or writing of this article.

\section{Authors' contributions}

AL collected, coded, and analysed the data of the current study. DW ensured the intercoder reliability for coding the data and participated in the analyses. All authors read and approved the final manuscript. 


\section{Acknowledgements}

Not applicable.

\section{References}

1. Huttner B, Harbarth S, Nathwani D, Policies ESG for A. Success stories of implementation of antimicrobial stewardship: a narrative review. Clin Microbiol Infect. 2014;20(10):954-62.

2. Karp BE, Tate H, Plumblee JR, Dessai U, Whichard JM, Thacker EL, et al. National Antimicrobial Resistance Monitoring System: Two Decades of Advancing Public Health Through Integrated Surveillance of Antimicrobial Resistance. Foodborne Pathog Dis. 2017 Oct;14(10):545-57.

3. Hiki M, Kawanishi M, Abo H, Kojima A, Koike R, Hamamoto S, et al. Decreased resistance to broad-spectrum cephalosporin in Escherichia coli from healthy broilers at farms in Japan after voluntary withdrawal of ceftiofur. Foodborne Pathog Dis. 2015;12(7):639-43.

4. Agunos A, Léger DF, Carson CA, Gow SP, Bosman A, Irwin RJ, et al. Antimicrobial use surveillance in broiler chicken flocks in Canada, 2013-2015. PLoS One [Internet]. 2017;12(6). Available from:

https://www.scopus.com/inward/record.uri?eid=2-s2.0-

85021627760\&doi=10.1371\%2Fjournal.pone.0179384\&partnerID=40\&md5=adcd743d4c7cd1f31ece79ad2aacd66e

5. [Anonymous]. Responsible Antimicrobial Use in the Canadian Chicken and Turkey Sectors, Version 2.0 [Internet]. 2015. Available from: http://www.chickenfarmers.ca/wp-content/uploads/2015/12/AMU-Booklet-June-2015EN.pdf

6. WHO. National Action Plans [Internet]. 2015. Available from: https://www.who.int/antimicrobial-resistance/nationalaction-plans/en/

7. Mölstad S, Cars O, Struwe J. Strama - A Swedish working model for containment of antibiotic resistance. Eurosurveillance. 2008;13(46):1-4.

8. Bordier M, Binot A, Pauchard Q, Nguyen DT, Trung TN, Fortané N, et al. Antibiotic resistance in Vietnam: moving towards a One Health surveillance system. BMC Public Health. 2018;18(1):1-14.

9. Fürst J, Čižman M, Mrak J, Kos D, Campbell S, Coenen S, et al. The influence of a sustained multifaceted approach to improve antibiotic prescribing in Slovenia during the past decade: Findings and implications. Expert Rev Anti Infect Ther. 2015;13(2):279-89.

10. Léger A, Lambraki I, Graells T, Cousins M, Henriksson PJ, Harbarth S, et al. AMR-Intervene: a social ecological framework to capture the diversity of actions to tackle antimicrobial resistance from a One Health perspective. J Antimicrob Chemother. 2020;dkaa394.

11. Wernli D, Jørgensen PS, Parmley EJ, Troell M, Majowicz S, Harbarth S, et al. Evidence for action: A One Health learning platform on interventions to tackle antimicrobial resistance. Lancet Infect Dis. 2020;

12. Madon T, Hofman KJ, Kupfer L, Glass RI. Implementation science. American Association for the Advancement of Science; 2007.

13. Lobb R, Colditz GA. Implementation Science and its Application to Population Health. Annu Rev Microbiol. 2013;34:235-51.

14. Johnson I, Hansen A, Bi P. The challenges of implementing an integrated One Health surveillance system in Australia. Zoonoses Public Health. 2018;65(1):e229-36.

15. Bordier M, Uea-Anuwong T, Binot A, Hendrikx P, Goutard FL. Characteristics of One Health surveillance systems: $A$ systematic literature review. Prev Vet Med [Internet]. 2018;(May):0-1. Available from: 
https://doi.org/10.1016/j.prevetmed.2018.10.005

16. Lee LM, Thacker SB, Louis MES. Principles and practice of public health surveillance - Third Edition. Oxford University Press, USA; 2010. 464 p.

17. Finegood DT. Can We Build an Evidence Base on the Impact of Systems Thinking for Wicked Problems? Int J Heal Policy Manag [Internet]. 2020; Available from: https://www.ijhpm.com/article_3927.html

18. Petticrew M, Knai C, Thomas J, Rehfuess EA, Noyes J, Gerhardus A, et al. Implications of a complexity perspective for systematic reviews and guideline development in health decision making. BMJ Glob Heal. 2019;4(Suppl 1).

19. Wernli D, Jørgensen PS, Harbarth S, Carroll SP, Laxminarayan R, Levrat N, et al. Antimicrobial resistance: The complex challenge of measurement to inform policy and the public. PLOS Med. 2017 Aug 17;14(8):e1002378.

20. Falagas ME, Bliziotis IA. Pandrug-resistant Gram-negative bacteria: the dawn of the post-antibiotic era? Int J Antimicrob Agents [Internet]. 2007;29(6):630-6. Available from:

http://www.sciencedirect.com/science/article/pii/S0924857907000192

21. Paterson DL. Resistance in gram-negative bacteria: Enterobacteriaceae. Am J Infect Control. 2006;34(5):S20-8.

22. Lambraki IA, Majowicz S, Parmley EJ, Wernli D, Léger A, Graells T, et al. A protocol for an integrated mixed-method approach to determining how to mitigate antimicrobial resistance across the One Health spectrum. submitted.

23. R Core Team. R: A language and environment for statistical computing [Internet]. Vienna, Austria.: Foundation for Statistical Computing, Vienna, Austria. ISBN 3-900051-07-0; 2020. Available from: http://www.r-project.org

24. Damschroder LJ, Aron DC, Keith RE, Kirsh SR, Alexander JA, Lowery JC. Fostering implementation of health services research findings into practice: a consolidated framework for advancing implementation science. Implement Sci. 2009;4(1):1-15.

25. Carroll SP, Jørgensen PS, Kinnison MT, Bergstrom CT, Denison RF, Gluckman P, et al. Applying evolutionary biology to address global challenges. Science (80- ). 2014;346(6207).

26. Jørgensen PS, Folke C, Carroll SP. Evolution in the Anthropocene: informing governance and policy. Annu Rev Ecol Evol Syst. 2019;50:527-46.

27. Jørgensen PS, Folke C, Henriksson PJG, Malmros K, Troell M, Zorzet A. Coevolutionary Governance of Antibiotic and Pesticide Resistance. Trends Ecol Evol. 2020;35(6):484-94.

28. Noyes J, Booth A, Moore G, Flemming K, Tunçalp Ö, Shakibazadeh E. Synthesising quantitative and qualitative evidence to inform guidelines on complex interventions: clarifying the purposes, designs and outlining some methods. BMJ Glob Heal. 2019;4(Suppl 1).

29. Klein EY, Van Boeckel TP, Martinez EM, Pant S, Gandra S, Levin SA, et al. Global increase and geographic convergence in antibiotic consumption between 2000 and 2015. Proc Natl Acad Sci. 2018;115(15):E3463-70.

30. McParland JL, Williams L, Gozdzielewska L, Young M, Smith F, MacDonald J, et al. What are the "active ingredients" of interventions targeting the public's engagement with antimicrobial resistance and how might they work? $\mathrm{Br} \mathrm{J}$ Health Psychol. 2018 May;23:804-19.

31. Booth A, Noyes J, Flemming K, Moore G, Tunçalp Ö, Shakibazadeh E. Formulating questions to explore complex interventions within qualitative evidence synthesis. BMJ Glob Heal. 2019;4(Suppl 1).

32. Booth A, Moore G, Flemming K, Garside R, Rollins N, Tunçalp Ö, et al. Taking account of context in systematic reviews and guidelines considering a complexity perspective. BMJ Glob Heal. 2019;4(Suppl 1).

33. Craig P, Di Ruggiero E, Frolich KL, Mykhalovskiy E, White M, Campbell R, et al. Taking account of context in population health intervention research: guidance for producers, users and funders of research. 2018;

34. Shoveller J, Viehbeck S, Di Ruggiero E, Greyson D, Thomson K, Knight R. A critical examination of representations of context within research on population health interventions. Crit Public Health [Internet]. 2016 Oct 19;26(5):487-500.

Page $12 / 22$ 
Available from: https://doi.org/10.1080/09581596.2015.1117577

35. Brakema E, van der Kleij R, Poot C, Chavannes NH, Tsiligianni I, Walusimbi S, et al. A systematic approach to context-mapping to prepare for health interventions: development and validation of the SETTING-tool in four countries. BMJ Glob Heal. 2021;6:e003221.

36. Rogers Van Katwyk S, Hoffman SJ, Mendelson M, Taljaard M, Grimshaw JM. Strengthening the science of addressing antimicrobial resistance: a framework for planning, conducting and disseminating antimicrobial resistance intervention research. Heal Res Policy Syst [Internet]. 2020;18(1):60. Available from: https://doi.org/10.1186/s12961-020-00549-1

37. Campbell M, Katikireddi SV, Hoffmann T, Armstrong R, Waters E, Craig P. TIDieR-PHP: a reporting guideline for population health and policy interventions. BMJ [Internet]. 2018 May 16;361:k1079. Available from:

http://www.bmj.com/content/361/bmj.k1079.abstract

38. Atkins L, Francis J, Islam R, O'Connor D, Patey A, Ivers N, et al. A guide to using the Theoretical Domains Framework of behaviour change to investigate implementation problems. Implement Sci [Internet]. 2017;12(1):77. Available from: https://doi.org/10.1186/s13012-017-0605-9

39. Anderson M, Schulze K, Cassini A, Plachouras D, Mossialos E. A governance framework for development and assessment of national action plans on antimicrobial resistance. Lancet Infect Dis [Internet]. 2019;19(11):e371-84. Available from: http://www.sciencedirect.com/science/article/pii/S1473309919304153

40. Price L, Gozdzielewska L, Young M, Smith F, MacDonald J, McParland J, et al. Effectiveness of interventions to improve the public's antimicrobial resistance awareness and behaviours associated with prudent use of antimicrobials: a systematic review. J Antimicrob Chemother [Internet]. 2018 Jun 1;73(6):1464-78. Available from: https://doi.org/10.1093/jac/dky076

41. Schweitzer VA, van Werkhoven $\mathrm{CH}$, Rodríguez Baño J, Bielicki J, Harbarth S, Hulscher M, et al. Optimizing design of research to evaluate antibiotic stewardship interventions: consensus recommendations of a multinational working group. Clin Microbiol Infect [Internet]. 2020;26(1):41-50. Available from: http://www.sciencedirect.com/science/article/pii/S1198743X1930477X

42. Norris SL, Rehfuess EA, Smith H, Tunçalp Ö, Grimshaw JM, Ford NP, et al. Complex health interventions in complex systems: improving the process and methods for evidence-informed health decisions. BMJ Glob Heal. 2019;4(Suppl 1).

43. Kruk ME, Ling EJ, Bitton A, Cammett M, Cavanaugh K, Chopra M, et al. Building resilient health systems: A proposal for a resilience index. BMJ. 2017;357.

44. Jørgensen PS, Wernli D, Folke C, Carroll SP. Changing antibiotic resistance: sustainability transformation to a promicrobial planet. Curr Opin Environ Sustain. 2017;25:66-76.

45. Musicha P, Cornick JE, Bar-Zeev N, French N, Masesa C, Denis B, et al. Trends in antimicrobial resistance in bloodstream infection isolates at a large urban hospital in Malawi (1998-2016): a surveillance study. Lancet Infect Dis. 2017 Oct;17(10):1042-52.

46. Leverstein-van Hall M, Fluit A, Blok H, Box A, Peters E, Weersink A, et al. Control of nosocomial multiresistant Enterobacteriaceae using a temporary restrictive antibiotic agent policy. Eur J Clin Microbiol Infect Dis. 2001;20(11):785-91.

47. Meyer E, Lapatschek M, Bechtold A, Schwarzkopf G, Gastmeier P, Schwab F. Impact of restriction of third generation cephalosporins on the burden of third generation cephalosporin resistant K. pneumoniae and E. coli in an ICU. Intensive Care Med. 2009;35(5):862-70.

48. Willemsen I, Cooper B, Van Buitenen C, Winters M, Andriesse G, Kluytmans J. Improving quinolone use in hospitals by using a bundle of interventions in an interrupted time series analysis. Antimicrob Agents Chemother.

Page 13/22 
2010;54(9):3763-9.

49. Lee RA, Scully MC, Camins BC, Griffin RL, Kunz DF, Moser SA, et al. Improvement of gram-negative susceptibility to fluoroquinolones after implementation of a pre-authorization policy for fluoroquinolone use: A decade-long experience. Infect Control Hosp Epidemiol. 2018 Dec;39(12):1419-24.

50. Ding H, Yang Y, Wei J, Fan S, Yu S, Yao K, et al. Influencing the use of antibiotics in a Chinese pediatric intensive care unit. Pharm world Sci. 2008;30(6):787-93.

51. Petrikkos G, Markogiannakis A, Papapareskevas J, Daikos GL, Stefanakos G, Zissis NP, et al. Differences in the changes in resistance patterns to third-and fourth-generation cephalosporins and piperacillin/tazobactam among Klebsiella pneumoniae and Escherichia coli clinical isolates following a restriction policy in a Greek tertiary care hospital. Int J Antimicrob Agents. 2007;29(1):34-8.

52. Kim N-H, Han W-D, Song K-H, Seo H, Shin M, Kim TS, et al. Successful containment of carbapenem-resistant Enterobacteriaceae by strict contact precautions without active surveillance. Am J Infect Control. 2014;42(12):1270-3.

53. De Champs C, Franchineau P, Gourgand JM, Loriette Y, Gaulme J, Sirot J. Clinical and bacteriological survey after change in aminoglycoside treatment to control an epidemic of Enterobacter cloacae. J Hosp Infect. 1994;28(3):219-29.

54. Ikeda Y, Mamiya T, Nishiyama H, Narusawa S, Koseki T, Mouri A, et al. A permission system for carbapenem use reduced incidence of drug-resistant bacteria and cost of antimicrobials at a general hospital in japan. Nagoya $\mathrm{J}$ Med Sci. 2012;74(1-2):93-104.

55. Chan YY, Lin TY, Huang CT, Deng ST, Wu TL, Leu HS, et al. Implementation and outcomes of a hospital-wide computerised antimicrobial stewardship programme in a large medical centre in Taiwan. Int J Antimicrob Agents. 2011;38(6):486-92.

56. Zou YM, Ma Y, Liu JH, Shi J, Fan T, Shan YY, et al. Trends and correlation of antibacterial usage and bacterial resistance: time series analysis for antibacterial stewardship in a Chinese teaching hospital (2009-2013). Eur J Clin Microbiol Infect Dis. 2015;34(4):795-803.

57. Hanberger H, Skoog G, Ternhag A, Giske CG. Antibiotic consumption and antibiotic stewardship in Swedish hospitals. Ups J Med Sci. 2014;119(2):154-61.

58. Altunsoy A, Aypak C, Azap A, Ergönül Ö, Balik I. The impact of a nationwide antibiotic restriction program on antibiotic usage and resistance against nosocomial pathogens in Turkey. Int J Med Sci. 2011;8(4):339-44.

59. Mölstad S, Löfmark S, Carlin K, Erntell M, Aspevall O, Blad L, et al. Lessons learnt during 20 years of the swedish strategic programme against antibiotic resistance [Programme stratégique suédois contre la résistance aux antibiotiques - 20 années d'enseignements]. Bull World Health Organ. 2017;95(11):764-73.

60. Turner PJ. Meropenem activity against European isolates: report on the MYSTIC (Meropenem Yearly Susceptibility Test Information Collection) 2006 results. Diagn Microbiol Infect Dis. 2008;60(2):185-92.

61. Jones RN, Mendes C, Turner PJ, Masterton R. An overview of the Meropenem Yearly Susceptibility Test Information Collection (MYSTIC) Program: 1997-2004. Diagn Microbiol Infect Dis. 2005;53(4):247-56.

62. Meyer E, Schwab F, Gastmeier P, Rueden H, Daschner FD. Surveillance of antimicrobial use and antimicrobial resistance in German intensive care units (SARI): A summary of the data from 2001 through 2004. Infection. 2006;34(6):303-9.

63. Meyer E, Schwab F, Gastmeier P, Rueden H, Daschner FD, Jonas D. Stenotrophomonas maltophilia and antibiotic use in German intensive care units: data from Project SARI (Surveillance of Antimicrobial Use and Antimicrobial Resistance in German Intensive Care Units). J Hosp Infect. 2006;64(3):238-43. 
64. Meyer E, Schwab F, Jonas D, Rueden H, Gastmeier P, Daschner FD. Surveillance of antimicrobial use and antimicrobial resistance in intensive care units (SARI): 1. Antimicrobial use in German intensive care units. Intensive Care Med. 2004;30(6):1089-96.

65. Agerso $\emptyset$ Y, Aarestrup FM. Voluntary ban on cephalosporin use in Danish pig production has effectively reduced extended-spectrum cephalosporinase-producing Escherichia coli in slaughter pigs. J Antimicrob Chemother. 2013;68(3):569-72.

66. Rhomberg PR, Deshpande LM, Kirby JT, Jones RN. Activity of meropenem as serine carbapenemases evolve in US Medical Centers: monitoring report from the MYSTIC Program (2006). Diagn Microbiol Infect Dis. 2007;59(4):42532.

67. Mölstad S, Erntell M, Hanberger H, Melander E, Norman C, Skoog G, et al. Sustained reduction of antibiotic use and low bacterial resistance: 10-year follow-up of the Swedish Strama programme. Lancet Infect Dis. 2008;8(2):12532.

68. Meyer E, Schwab F, Jonas D, Ruden H, Gastmeier P, Daschner FD. Temporal changes in bacterial resistance in German intensive care units, 2001-2003: Data from the SARI (surveillance of antimicrobial use and antimicrobial resistance in intensive care units) project. J Hosp Infect. 2005;60(4):348-52.

69. Meyer E, Jonas D, Schwab F, Rueden H, Gastmeier P, Daschner FD. Design of a surveillance system of antibiotic use and bacterial resistance in German intensive care units (SARI). Infection. 2003;31(4):208-15.

70. Hammerum AM, Heuer OE, Emborg HD, Bagger-Skjøt L, Jensen VF, Rogues AM, et al. Danish integrated antimicrobial resistance monitoring and research program. Emerg Infect Dis. 2007;13(11):1632-9.

71. Kadykalo S V, Anderson MEC, Alsop JE. Passive surveillance of antimicrobial resistance in Salmonella and Escherichia coli isolates from Ontario livestock, 2007-2015. Can Vet J = La Rev Vet Can. 2018 Jun;59(6):617-22.

72. Zhang P, Shen Z, Zhang C, Song L, Wang B, Shang J, et al. Surveillance of antimicrobial resistance among Escherichia coli from chicken and swine, China, 2008-2015. Vet Microbiol. 2017 May;203:49-55.

73. de Jong A, Garch F El, Simjee S, Moyaert H, Rose M, Youala M, et al. Monitoring of antimicrobial susceptibility of udder pathogens recovered from cases of clinical mastitis in dairy cows across Europe: VetPath results. Vet Microbiol. 2018 Jan;213:73-81.

74. Kaspersen H, Urdahl AM, Simm R, Slettemeas JS, Lagesen K, Norstrom M. Occurrence of quinolone resistant E. coli originating from different animal species in Norway. Vet Microbiol. 2018 Apr;217:25-31.

75. Boireau C, Morignat E, Cazeau G, Jarrige N, Jouy E, Haenni M, et al. Antimicrobial resistance trends in Escherichia coli isolated from diseased food-producing animals in France: A 14-year period time-series study. Zoonoses Public Health. 2018 Feb;65(1):e86-94.

76. Callens B, Cargnel M, Sarrazin S, Dewulf J, Hoet B, Vermeersch K, et al. Associations between a decreased veterinary antimicrobial use and resistance in commensal Escherichia coli from Belgian livestock species (20112015). Prev Vet Med. 2018 Sep;157:50-8.

77. Denisuik AJ, Garbutt LA, Golden AR, Adam HJ, Baxter M, Nichol KA, et al. Antimicrobial-resistant pathogens in Canadian ICUs: results of the CANWARD 2007 to 2016 study. J Antimicrob Chemother. 2018 Nov;

78. Johnson AP. Surveillance of antibiotic resistance. Philos Trans R Soc B Biol Sci. 2015;370(1670).

79. Vikram A, Rovira P, Agga GE, Arthur TM, Bosilevac JM, Wheeler TL, et al. Impact of "Raised Without Antibiotics" Beef Cattle Production Practices On Occurrences of Antimicrobial Resistance. Appl Environ Microbiol. 2017 Sep;

80. Remschmidt C, Schneider S, Meyer E, Schroeren-Boersch B, Gastmeier P, Schwab F. Surveillance of Antibiotic Use and Resistance in Intensive Care Units (SARI). Dtsch Arztebl Int. 2017 Dec;114(50):858-65.

81. MacKinnon MC, Pearl DL, Carson CA, Parmley EJ, McEwen SA. Comparison of annual and regional variation in multidrug resistance using various classification metrics for generic Escherichia coli isolated from chicken abattoir 
surveillance samples in Canada. Prev Vet Med. 2018 Jun;154:9-17.

82. Jensen US, Muller A, Brandt CT, Frimodt-Møller N, Hammerum AM, Monnet DL, et al. Effect of generics on price and consumption of ciprofloxacin in primary healthcare: the relationship to increasing resistance. J Antimicrob Chemother. 2010;65(6):1286-91.

83. Korzeniewska E, Harnisz M. Relationship between modification of activated sludge wastewater treatment and changes in antibiotic resistance of bacteria. Sci Total Environ. 2018 Oct;639:304-15.

84. Davies J, Johnson AP, Hope R. Identifying hospital-onset Escherichia coli bacteraemia cases from English mandatory surveillance: the case for applying a two-day post-admission rule. J Hosp Infect. 2017 Nov;97(3):20711.

85. Abernethy J, Guy R, Sheridan EA, Hopkins S, Kiernan M, Wilcox MH, et al. Epidemiology of Escherichia coli bacteraemia in England: results of an enhanced sentinel surveillance programme. J Hosp Infect. 2017 Apr;95(4):365-75.

86. Dharmarha V, Pulido N, Boyer RR, Pruden A, Strawn LK, Ponder MA. Effect of post-harvest interventions on surficial carrot bacterial community dynamics, pathogen survival, and antibiotic resistance. Int J Food Microbiol. 2019 Feb;291:25-34.

87. Dutil L, Irwin R, Finley R, Ng LK, Avery B, Boerlin P, et al. Ceftiofur resistance in Salmonella enterica serovar Heidelberg from chicken meat and humans, Canada. Emerg Infect Dis. 2010;16(1):48-54.

88. Rummukainen $M L$, Jakobsson A, Matsinen $M$, Järvenpää $S$, Nissinen $A$, Karppi $P$, et al. Reduction in inappropriate prevention of urinary tract infections in long-term care facilities. Am J Infect Control [Internet]. 2012;40(8):711-4. Available from: http://dx.doi.org/10.1016/j.ajic.2011.09.013

89. Gottesman BS, Carmeli Y, Shitrit P, Chowers M. Impact of quinolone restriction on resistance patterns of Escherichia coli isolated from urine by culture in a community setting. Clin Infect Dis. 2009;49(6):869-75.

90. Fridkin SK, Steward CD, Edwards JR, Pryor ER, McGowan Jr JE, Archibald LK, et al. Surveillance of antimicrobial use and antimicrobial resistance in United States hospitals: project ICARE phase 2. Clin Infect Dis. 1999;29(2):245-52.

91. der Kuil W, Schoffelen AF, de Greeff SC, Thijsen SFT, Alblas HJ, Notermans DW, et al. National laboratory-based surveillance system for antimicrobial resistance: a successful tool to support the control of antimicrobial resistance in the Netherlands. Eurosurveillance [Internet]. 2017;22(46). Available from:

https://www.scopus.com/inward/record.uri?eid=2-s2.0-85034982946\&doi=10.2807\%2F1560-

7917.ES.2017.22.46.17-00062\&partnerID=40\&md5=fa627714da282a53e18616bcd6566f2a

92. Dorado-García A, Mevius DJ, Jacobs JJH, Van Geijlswijk IM, Mouton JW, Wagenaar JA, et al. Quantitative assessment of antimicrobial resistance in livestock during the course of a nationwide antimicrobial use reduction in the Netherlands. J Antimicrob Chemother. 2016;71(12):3607-19.

\section{Tables}

Table 1: Summary of the main characteristics identified from studying the 42 interventions coded to highlight the main features of the interventions for each building block in the AMR-Intervene database with the smallest/most narrow, largest/most broad, and most common value for selected variables of AMRIntervene 


\begin{tabular}{|c|c|c|c|}
\hline Variable & Minimum & Typical intervention & Maximum \\
\hline $\begin{array}{l}\text { Start year of the } \\
\text { intervention }\end{array}$ & 1982 & 2004 & 2012 \\
\hline $\begin{array}{l}\text { Duration of the } \\
\text { intervention }\end{array}$ & 1 year (7/42) & $\begin{array}{l}\text { Ongoing intervention } \\
\text { when assessed (27/42) }\end{array}$ & 7 years $(1 / 42)$ \\
\hline Country of implementation & One country (40/42) & One HIC (36/42) & $\begin{array}{l}\text { Several countries } \\
\text { involved }(2 / 42)\end{array}$ \\
\hline Level of implementation & $\begin{array}{l}\text { One level of implementation } \\
(37 / 42)\end{array}$ & National (16/42) & $\begin{array}{l}\text { Several levels involved } \\
(5 / 42)\end{array}$ \\
\hline Sector & $\begin{array}{l}\text { One sector of implementation } \\
\text { (human or animal, } 37 / 42 \text { ) }\end{array}$ & Human sector (25/42) & $\begin{array}{l}\text { Several sector involved } \\
\text { (not frequent, } 3 / 42 \text { ) }\end{array}$ \\
\hline Social system & $\begin{array}{l}\text { No specific social group } \\
\text { targeted }(26 / 42)\end{array}$ & $\begin{array}{l}\text { No specific social group } \\
\text { targeted }(26 / 42)\end{array}$ & $\begin{array}{l}\text { Several social groups } \\
\text { targeted }(29 / 42)\end{array}$ \\
\hline $\begin{array}{l}\text { Number of bacteria } \\
\text { targeted }\end{array}$ & $\begin{array}{l}\text { No specific bacteria targeted } \\
(13 / 42)\end{array}$ & $\begin{array}{l}\text { Enterobacteriaceae } \\
(29 / 42)\end{array}$ & $\begin{array}{l}\text { Three bacteria targeted } \\
(3 / 42)\end{array}$ \\
\hline Number of AM targeted & $\begin{array}{l}\text { No specific AM classes } \\
\text { targeted }(9 / 42)\end{array}$ & Betalactams (26/42) & $\begin{array}{l}7 \text { AM classes targeted } \\
(3 / 42)\end{array}$ \\
\hline Responsible & $\begin{array}{l}\text { One institution responsible } \\
(28 / 42)\end{array}$ & $\begin{array}{l}\text { Governmental } \\
\text { institution (21/42) }\end{array}$ & Partnership (2/42) \\
\hline Funding source & Privately funded (3/42) & $\begin{array}{l}\text { Government funded } \\
(38 / 42)\end{array}$ & Partnership (1/42) \\
\hline $\begin{array}{l}\text { Type of policy instrument } \\
\text { used by the intervention }\end{array}$ & $\begin{array}{l}\text { One type of policy instrument } \\
(29 / 42)\end{array}$ & Regulation (19/42) & Two types (7/42) \\
\hline Trigger & On trigger $(31 / 38)$ & State (15/42) & $\begin{array}{l}3 \text { different types of } \\
\text { trigger }(1 / 42)\end{array}$ \\
\hline Goal & One goal (28/42) & State (16/42) & $\begin{array}{l}3 \text { different types of } \\
\text { goals }(2 / 42)\end{array}$ \\
\hline $\begin{array}{l}\text { Challenge of collective } \\
\text { action }\end{array}$ & One challenge (34/42) & Surveillance (18/42) & $\begin{array}{l}3 \text { different types of } \\
\text { challenges }(1 / 42)\end{array}$ \\
\hline $\begin{array}{l}\text { Leverage point of the } \\
\text { intervention }\end{array}$ & & $\begin{array}{l}\text { Low leverage point } \\
(36 / 42)\end{array}$ & \\
\hline $\begin{array}{l}\text { Number of key results } \\
\text { assessed }\end{array}$ & One key result (6/52) & $\begin{array}{l}3 \text { key results assessed } \\
(16 / 52)\end{array}$ & $\begin{array}{l}\text { Five or more key results } \\
(4 / 52)\end{array}$ \\
\hline
\end{tabular}

The table gathers the main characteristics identified from studying the 42 interventions coded to highlight the main features of the interventions for each building block in the AMR-Intervene database with the smallest/most narrow, largest/most broad, and most common value for selected variables of AMRIntervene.

Table 2: Details of success and failure factors and contextual factors identified in the 52 studied publications 


\begin{tabular}{lll}
\hline $\begin{array}{l}\text { Main domain } \\
\text { of CFIR }\end{array}$ & Subdomain of & Description of the factor (success, failure, or contextual factor) \\
classification & CFIR & classification
\end{tabular}

Interventions Importance of characteristics evidence strength and quality

(n)

Adaptability.

Complexity of intervention.

Success factor: A proper strategy for data access, management, and analysis was identified as a success factor. Data should also be checked for plausibility and completeness.

Failure factors: Several publications highlighted data limitations as potential failure factors of their intervention, including small number of data/samples, quality of the data (e.g., sampling, recording, entering the data in the database, consistency of data recording, bias in data collection, quality control, semantic homogeneity), low representativeness of the data, and the need for long-time data.

Some authors also mentioned the lack of adequate literature and knowledge to help them conducting their research.

Success factor: Interventions were reported more successful if individually tailored regarding their features and methods while remaining flexible to adapt along with the intervention lifecycle. Activities that were adapted or changed as needed during their lifecycle were more likely to be accepted, useful, and to successfully lead to intended outcomes. For instance, some interventions changed AMU guidelines, expanded the scope of a surveillance system, and conducted or recommended that interventions be evaluated throughout their lifecycle.

Success factors: Multimodal interventions were also reported to increase the success of interventions. For example, one activity such as surveillance of AMU in animals can be supported by several others like guideline implementation, awareness campaigns, group discussions, and media dissemination. Interdisciplinary teams and collaboration between disciplines was identified several times as a catalyst for success. It has been suggested as a factor of success but also an empowering factor for achieving goals. Early involvement of all actors (e.g., stakeholders, multidisciplinary actors) was another supportive action for the intervention.

Decentralising actions to regional and local groups with a diversity and multiplicity of actors was considered to increase the success of the interventions. Also, embedding the intervention in pre-existing structures and using existing resources (e.g., sampling strategy already in place) and collaboration with local scientific and political partners may increase the success of the intervention.

Costs.

Success factor: Interventions were identified as costly and require a sustainable financial support to access data and maintain activities.

Outer and inner setting
Networks and communication.
Success factors: The communication with the general public, sometimes with the collaboration with media, was a real asset for intervention to increase acceptability but also visibility, transparency, and support.

Communication within the intervention team and actors was important to encourage the implication and compliance to the intervention. Feedback from actors was also necessary for adapting the intervention if its design did not fit its purpose.

\section{Collaboration and participation.}

External policies and incentives.
Contextual factors: Interventions at the national level that were implemented concurrently with the studied intervention made an independent assessment of the intervention's impact difficult, and it might have increased its acceptability/compliance within the target population (e.g., surveillance system and vaccination programme).

Access to healthcare was found to have an influence in the access of AMs, their use, and willingness of people to be treated (e.g., lack of health insurance policy). 
Culture.

Contextual factor: A commitment for AMR control in the country was found to make an intervention better accepted by the actors and targeted population.

However, a track record of actions against AMR was also suggested to lead to smaller impact of the intervention, as the previous interventions already improved the situation regarding AMR in the country. This might reflect the diminishing return of some action with a low leverage point. Nonetheless, having functioning institutions in a state, which ensures compliance with interventions, is an essential cornerstone for limiting AMR.

Process $\quad$ Engaging. $\quad$ Failure factor: The lack of results was also related to the lack of incentives to participate and follow instructions of the intervention.

Success factors: Direct and strong support from the hierarchy was mentioned as a factor to enhance success of the intervention by providing leadership and support. Assigning clear responsibilities for the intervention can also contributed to successful intervention implementation. The funding of a specific coordinator or assistant within the intervention was also described as important.

Threshold for

intervention

Failure factor: Threshold for intervention effectiveness reached was identified

effectiveness. in one publication which mentioned that the intervention implemented in the country could have reached the limits of effectiveness.

Details of success and failure factors and contextual factors that had an impact on the interventions as described in the 52 studied publications, following the classification of the CFIR framework (Consolidated Framework for Implementation Research) developped by Damschroder et al. (24).

\section{Figures}

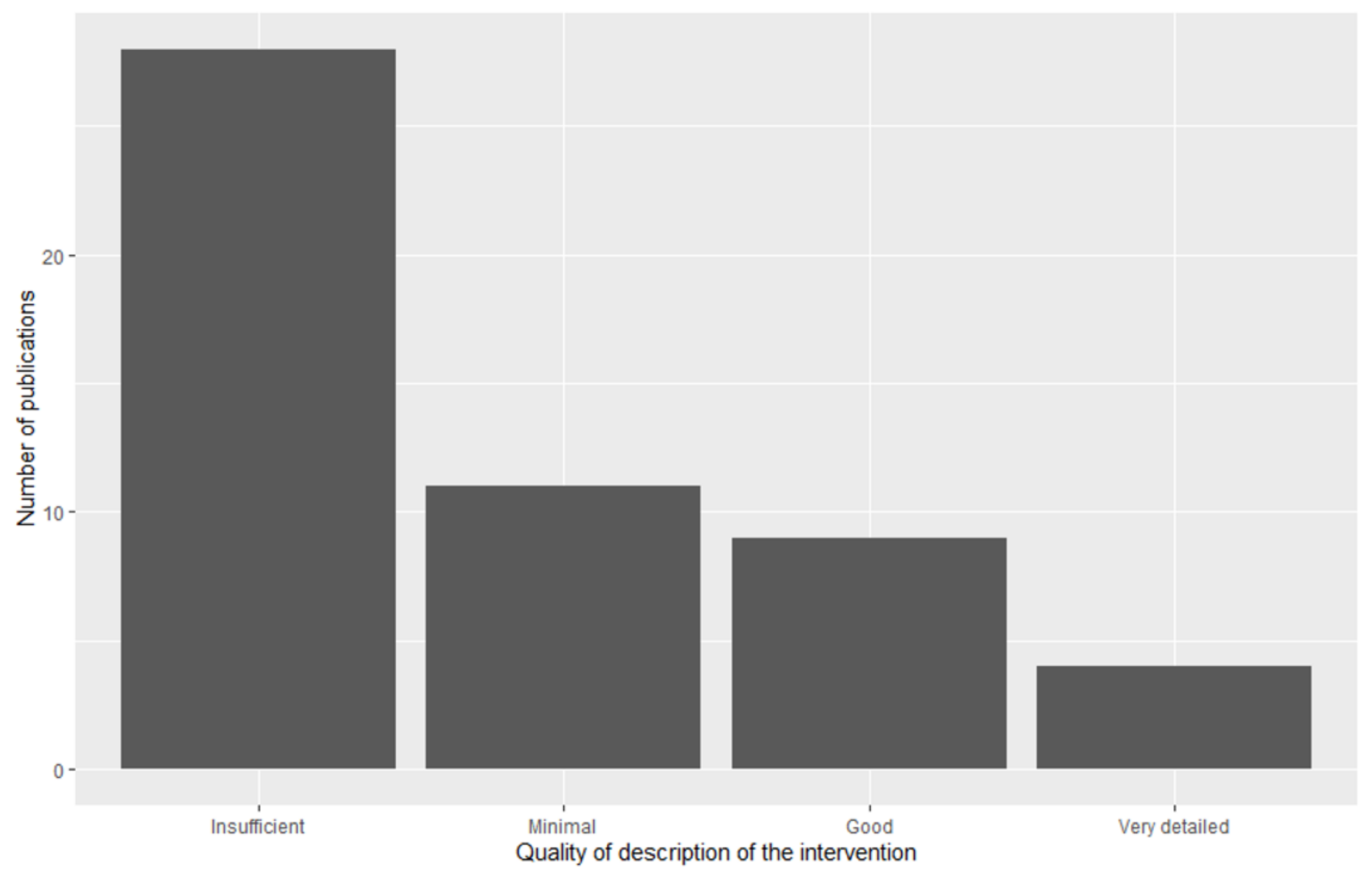




\section{Figure 1}

Results of the qualitative assessment of description of the intervention in the scientific publications ( $n=52$ articles coded)

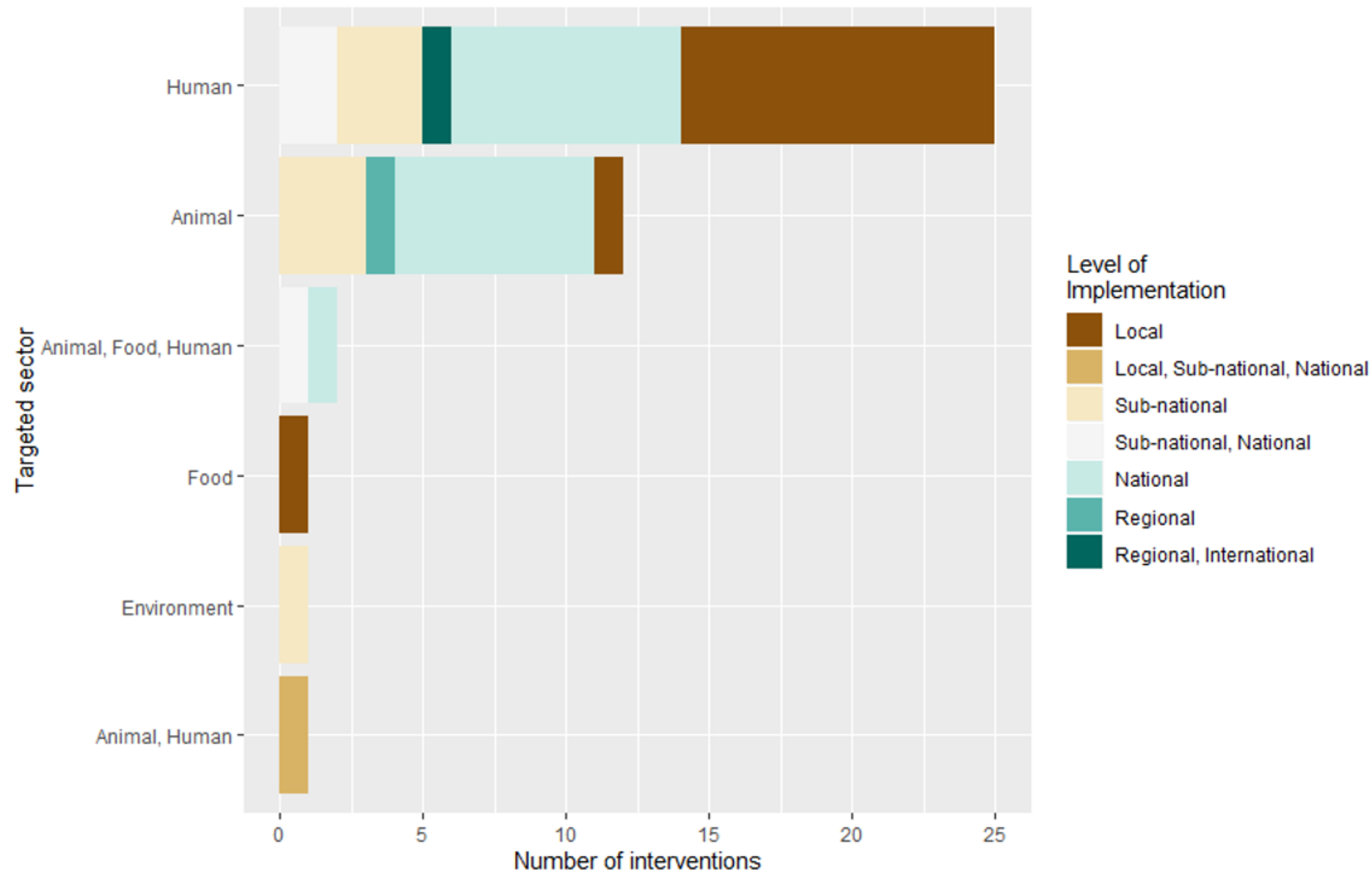

\section{Figure 2}

Targeted sector of the E. coli AMR interventions depending on their level of implementation ( $n=42$ E. coli AMR interventions from 52 articles coded) 


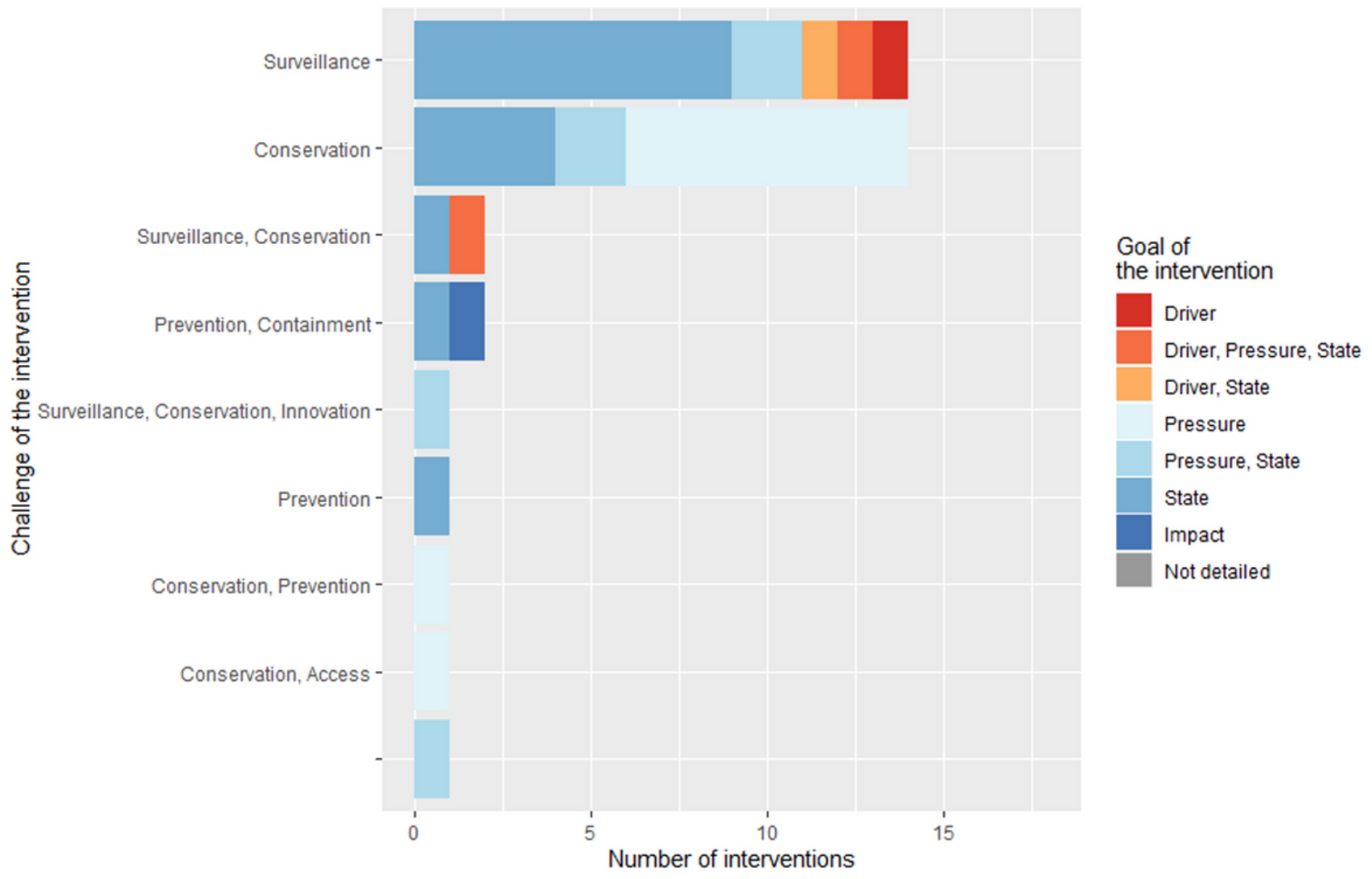

\section{Figure 3}

Challenge of the implementation of the E. coli AMR intervention in relation to the goal of the intervention ( $n=42 \mathrm{E}$. coli AMR interventions from 52 articles coded)

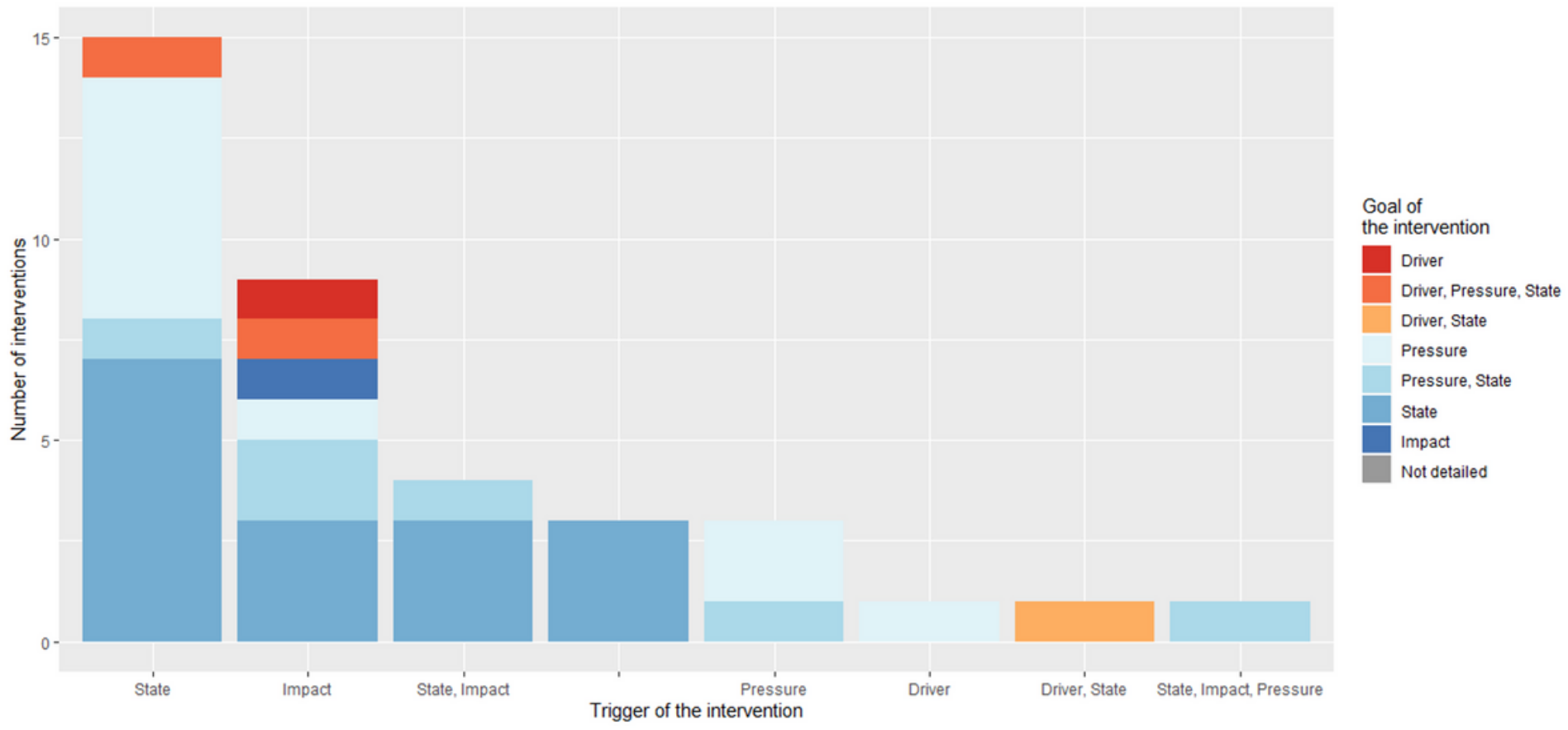




\section{Figure 4}

Trigger of the E. coli AMR interventions in relation to the goal of the intervention ( $n=42 \mathrm{E}$. coli AMR interventions from 53 articles coded)

\section{Supplementary Files}

This is a list of supplementary files associated with this preprint. Click to download.

- ADDFILES1paperEcoli20210125.docx

- ADDFILES2paperEcoli20210125.docx

- ADDFILES3paperEcoli20210125.docx 